\title{
Cultural experiences of immigrant nurses at two hospitals in Chile
}

\author{
Gabriel Rodríguez ${ }^{1}$ \\ Luz Angélica-Muñoz ${ }^{2}$ \\ Luiza Akiko Komura Hoga ${ }^{3}$
}

Objective: to explore the cultural experiences of nurses who immigrated to Chile. The study's theoretical framework was the Purnell Model for Cultural Competence. Method: Leininger's Observation-Participation-Reflection method was developed at two hospitals in the city of Santiago, and ethnographic interviews were held with 15 immigrant nurses. Results: among Purnell's 12 domains, the following were identified: Overview/heritage, Communication, Workforce issues, Family roles and organization, Biocultural ecology and Health-care practices. The difficulties were related to the language and its semantic meaning, the new responsibilities and the difficult relationship with colleagues. "In search of better horizons - the decision to immigrate", "Gaining confidence and establishing a support network - employability and professional performance" and "Seeking for people's acceptance - professional adaptation in a new cultural scenario" are cultural themes that represent their experiences. Conclusions: the competence to offer cultural care demands the development of public policies and continuing education programs at health institutions, specifically focused on immigrant nurses.

Descriptors: Nurses; Emigration and Immigration; Qualitative Research; Anthropology, Cultural; Nursing Staff, Hospital.

\footnotetext{
${ }^{1} \mathrm{PhD}$, Professor, Facultad de Enfermería, Universidad Andrés Bello, Santiago, Chile.

2 PhD, Full Professor, Facultad de Enfermería, Universidad Andrés Bello, Santiago, Chile.

${ }^{3}$ PhD, Associate Professor, Escola de Enfermagem, Universidade de São Paulo, São Paulo, SP, Brazil.
}

Corresponding Author:

Gabriel Rodríguez

Universidad Andres Bello. Facultad de Enfermería

Av. República, 237

Centro

26618476, Santiago, Chile

E-mail: gdriguez@gmail.com
Copyright (c) 2014 Revista Latino-Americana de Enfermagem This is an Open Access article distributed under the terms of the Creative Commons Attribution Non-Commercial License (CC BY-NC).

This license lets others distribute, remix, tweak, and build upon your work non-commercially, and although their new works must also acknowledge you and be non-commercial, they don't have to license their derivative works on the same terms. 


\section{Introduction}

Studies focusing on the experiences of the nurses who migrated to countries like Australia, the United States and Canada identified cultural barriers such as marginalization, language difficulties, devaluation of professional skills and development of limited and stressful relations with colleagues ${ }^{(1-3)}$.

In an unpublished multicenter research concluded by the Pan American Health Organization (PAHO) entitled "Migración de Enfermeras de América Latina: Área de América de Sur", published in the Series No. 60 of Human Resources for Health(4), some experiences of professionals in countries in the region were analyzed. According to the same study, the most frequent emigration reasons for the nurses who traveled to Chile were related to family, politics, insecurity, economy, cultural conditions and personal development.

The poor economic situation, lack of employment and professional development opportunities and lack of beneficial work policies for the general population, which directly affect the nursing professionals, are the main reasons that characterize the central phenomenon of these professionals' migration.

Personal development, economic stability and working in satisfactory professional conditions are their aspirations, but signaled difficult employability. In addition, they identified three moments in their migration trajectory: the decision to emigrate, the travel and the initial establishment in the country of destiny, and professional and social consolidation ${ }^{(4)}$.

The reasons for nurses to migrate to Argentina were related to family, economy and professional development, in order of importance.

The difficulties Brazilian immigrant nurses faced were the language and the cultural differences. Although nurses who immigrated to Venezuela expressed satisfaction with their achievements, regarding their professional life as well as their life projects, they indicate difficulties to combine the roles of mother, wife and professionals and experience feelings of rootlessness, conflicts that make them feel vulnerable ${ }^{(4)}$. For some time, the immigrant nursing professionals face difficulties in the employability process in another country.

In this context, there is a global crisis affecting the population, which involves the shortage of health personnel, the lack of experts, the deficit in health prevention and promotion and the migration of professionals. This leads towards the marketing of services at the cost of their professional ideals, the loss of confidence and the demotivation of health professionals $^{(5)}$.

The trends in this new post-modern order are reflected in the nursing work and services and efforts should be made to overcome the status quo, as the source of all energy to achieve the change derives from the human capital. This leads us to the social responsibility universities and health organizations and services should assume towards the citizens ${ }^{(6)}$.

The health professionals need to promote the growth, development, communication and preservation of knowledge inside institutions, so that nursing management ultimately permits the achievement of rapid and assertive responses in decision making in clinical practice(7).

This research was undertaken in view of the existence of distinct characteristics of nursing professionals regarding the educative, socio-economic, family and behavioral aspects, according to the country and its cultural context. The research question was: "How do the nurses who migrate to Chile to work have experienced the new culture found in this country?".

The study objective was to explore the cultural experiences of nurses who migrated to Chile to practice their profession.

The exploration and description of these experiences can contribute to offer support to immigrant nursing professionals. They are also essential for the health institutions who receive them, with a view to planning actions for the welcoming and integration of the foreign professionals in the new work context.

Hence, the immigrant nurses urgently need to be integrated into the new and unknown cultural environment and to adapt to the standards, beliefs and values that prevail in the new social and care context.

\section{Method}

The explored theme was approached through the qualitative paradigm. The ethnography was the method used to discover the cultural symbols permeating the immigrant nurses' daily care practices and to permit the contact with the range of conflicts that will be revealed in the discovery of their experiences.

The Observation-Participation-Reflection (OPR) Model proposed by Leininger was done ${ }^{(8)}$. The data collection started with the observation phase and the impressions were registered in a field diary, incorporating aspects of the dynamics, relationship and work environment of the immigrant nurses. This 
was gradually replaced by the participation in the daily activities in the cultural scenarios, which was facilitated by the fact that the primary author of the study was a nurse at one of the institutions studied and an immigrant in Chile.

We used Leininger's OPR as a methodological framework, considering its nature and applicability in this research, to explore and understand the cultural symbols permeating the nurse's daily practices.

The Purnell Model for Cultural Competence was this study's theoretical framework. The main premise of this framework is that all care professionals need to know the culture with a view to providing culturally competent care ${ }^{(9)}$. According to Purnell, cultural awareness is developed in a non-linear process that involves the phases of cultural adaptation, ranging from unconsciously incompetent for care practice, followed by the levels of consciousness about the incompetence, competence, until reaching the level that is considered ideal, marked by unconscious competence to provide health care in a way that is considered appropriate to the predominant beliefs and cultural values in the new cultural care context $^{(9)}$. This Model is flexible and applicable to a range of professional areas and contexts and includes individual, family, community and social aspects. For its application, it contains 12 related cultural domains: overview/heritage, communication, gender roles and family organization, workforce issues, biocultural ecology, high-risk behaviors, nutrition, pregnancy, death rituals, spirituality, healthcare practices and health-care providers. Figure 1 summarizes these domains.

Purnell's premises allow us to incorporate the Model in the experiences of nurses who arrive to work in the new country.

The study was developed in two cultural contexts, called Hospital 1 and Hospital 2 in this study. Hospital 1 is one of the largest care centers in the country and offers the largest number of medical specialties and subspecialties, attending to a population in the South of Santiago; health care is provided to hospitalized patients, who arrive through outpatient clinics as well as emergency care. Hospital 2 does not deliver emergency care and provides health care to adult patients, offering comprehensive care to people in the Southeast of Santiago. Both hospitals are affiliated with the public system and are located in the capital of Chile.

In this study, all foreign nurses hired in both hospitals were included. Data were collected between
March and May 2010 at Hospital 1 and between June and August of the same year at Hospital 2.

The criteria for inclusion in the study were: being an immigrant nurse, graduated in the country of origin, at least one year of professional practice in Chile, having a job contract in one of the two cultural contexts and being willing to cooperate with this study. The 15 foreign nurses from the two hospitals were invited to participate in this research and served as key informants ${ }^{(8)}$. None of them refused to participate.

The contact with the professionals took place on a date and time scheduled by phone or personally with each nurse. The primary investigator started the observation phase when he arrived at the service where the nurses work. First, it was registered that the professionals constantly moved around between the nurses' station and the patients' rooms and interacted agreeably with their colleagues and other care team members, such as physicians and auxiliary nurses.

The observation phase took place during the researcher's stay, while the participation phase was developed in two parts; in the first, the researcher accompanied the nurses in their care activities. During these moments, the researcher had the impression that the professionals felt they were being evaluated while justifying each of their actions and/or procedures. When the primary investigator has acquired familiarity with the cultural and work context, he started the second part of the participation phase, which involved cooperating in some nursing care activities. In this phase, the interviews with the research informants started.

The mean duration of the interviews was 68 minutes, and descriptive, structural and contrast questions were used $^{(8)}$. These were fully recorded, listened to in private, transcribed and stored in an exclusive file by the primary investigator. The collected data were complemented by the written notes taken during the field observation process $^{(10)}$.

The study complied with the ethical requisites ${ }^{(11)}$ and received approval from the Ethics Committee at Facultad de Enfermería de la Universidad Andrés Bello. After the research participants in both hospitals had received clarifications, the data collection was started. Ethical standards were previously informed and complied with through the signing of the informed consent term by all professionals.

The data were analyzed by the primary investigator and the other authors, in accordance with Leininger's proposal. The themes the participants addressed were 
grouped in Purcell's involved domains. The collected data were validated as established in the OPR method(8), involving four nurses, two from each hospital. As part of the key informants, they agreed with the data and cultural themes the investigators had elaborated.
The contents of the cultural themes are supported and exemplified by small quotes extracted from the nurses' narratives, who were identified through fictitious names and the respective countries of origin, with the country's official abbreviation.

\section{The Purnell Model for Cultural Competence}

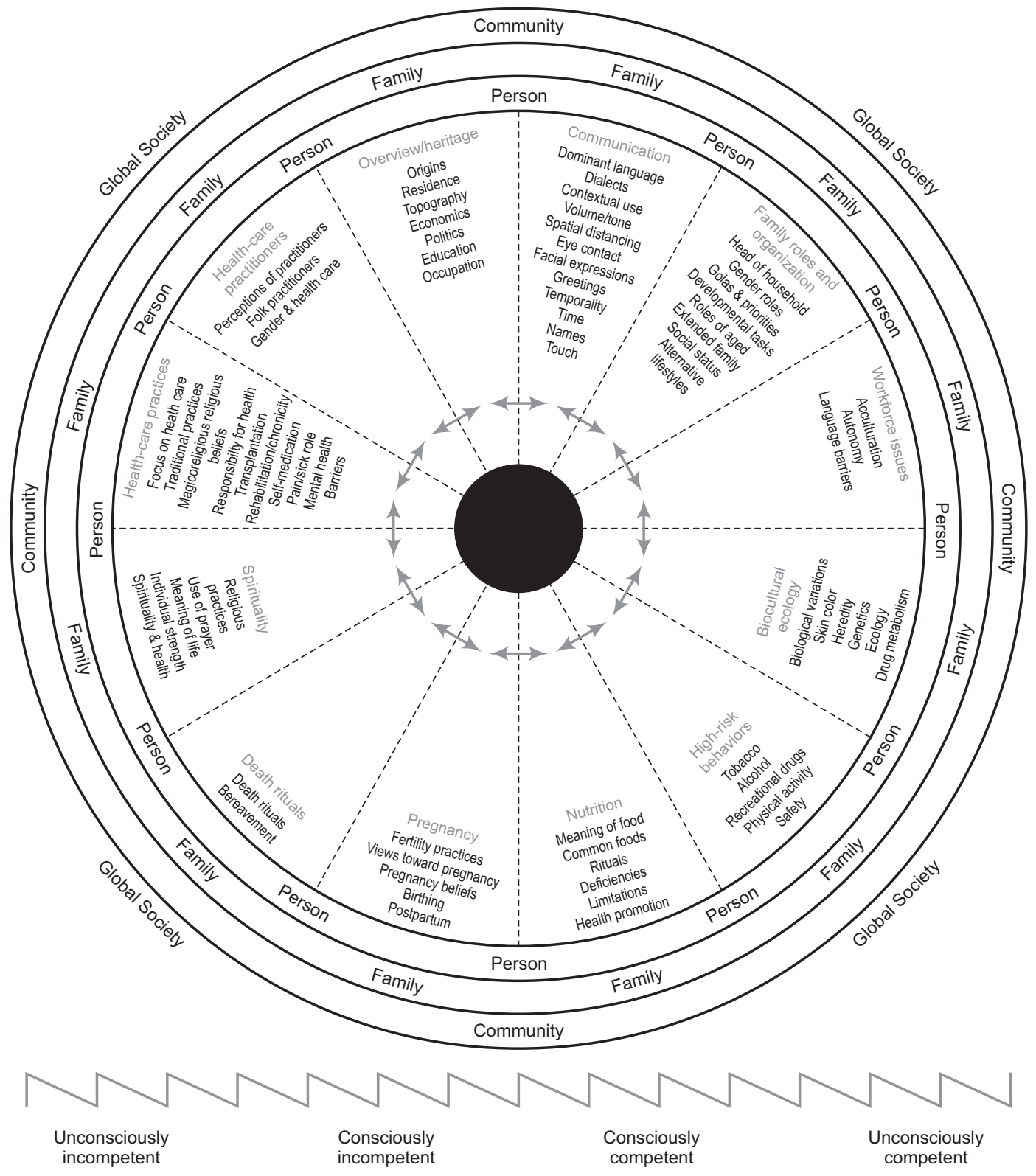

Primary characteristics of culture: age, generation, nationality, race, color, gender, religion

Secondary characteristics of culture: educational status, socioeconomic status, occupation, military status, political beliefs, urban versus rural residence, enclave identity, marital status, parental status, physical characteristics, sexual orientation, gender issues, and reason for migration (sojourner, immigrant, undocumented status)

Unsconsciously incompetent: not being aware that one is lacking knowledge about another culture

Consciously incompetent: being aware that one is lacking knowledge about another culture

Consciously competent: learning about the client s culture, verifying generalizations about the client s culture,

and providing culturally specific interventions

Unsconsciously competent: automatically providing culturally congruent care to clients of diverse cultures

Model created by Larry D. Purnell, Phd, RN, FAAN. Reprinted with permission.

License number 337210054442

Figure 1 - The Purnell Model for Cultural Competence, 2002(9) 


\section{Results}

The immigrant nurses were young and came from Brazil (1), Colombia (7), Ecuador (3) and Uruguay (4). Their skin color ranged between white and mulatto, they lived with a fixed partner, most had worked in the country for less than five years and only one held a graduate degree.

In Table 1, the sociodemographic and professional characteristics of the immigrant nurses are presented

Table 1 - Sociodemographic and professional characteristics of the immigrant nurses in Chile, Santiago, Chile, 2010

\begin{tabular}{|c|c|c|c|c|c|c|}
\hline $\begin{array}{c}\text { Name } \\
\text { (fictitious) }\end{array}$ & $\begin{array}{c}\text { Age } \\
\text { (years) }\end{array}$ & Country of origin & Skin color & Marital status & $\begin{array}{c}\text { Length of professional } \\
\text { experience in Chile (years) }\end{array}$ & Highest degree \\
\hline María & 28 & Colombia & White & Single & 3 & Bachelor \\
\hline Melissa & 27 & Colombia & White & Fixed partner & 3 & Bachelor \\
\hline Andrea & 44 & Brazil & White & Fixed partner & 1 & Ph.D. \\
\hline Berta & 27 & Colombia & White & Fixed partner & 3 & Bachelor \\
\hline Lucía & 28 & Colombia & Mulatto & Fixed partner & 3 & Bachelor \\
\hline Amanda & 33 & Ecuador & Mulatto & Married & 5 & Bachelor \\
\hline Cristina & 42 & Ecuador & Mulatto & Married & 12 & Bachelor \\
\hline Estela & 24 & Colombia & White & Fixed partner & 3 & Bachelor \\
\hline Diana & 27 & Uruguay & White & Single & 1 & Bachelor \\
\hline Isabel & 28 & Colombia & Mulatto & Married & 1 & Bachelor \\
\hline Gladys & 28 & Uruguay & White & Single & 1 & Bachelor \\
\hline Nieves & 27 & Uruguay & White & Single & 1 & Bachelor \\
\hline Lorena & 34 & Uruguay & White & Single & 2 & Bachelor \\
\hline Karen & 32 & Ecuador & Mulatto & Separated & 7 & Specialist \\
\hline Iris & 28 & Colombia & White & Single & 4 & Bachelor \\
\hline
\end{tabular}

The six cultural domains from the Purnell Model related to the experiences of the immigrant nurses in Chile are: Overview/heritage, Communication, Family roles and organization, Workforce issues, Biocultural ecology, Health-care practices and Healthcare providers ${ }^{(9)}$, which were grouped in three cultural themes: "In search of better horizons - the decision to immigrate", "Gaining trust and establishing a support network - employability and professional performance" and "Seeking people's acceptance - professional adaptation in a new cultural scenario". The immigrant nurses make great efforts to overcome the different difficulties, observing that the people are different. For them, this means making contact as persons in order to be respected and respect the others.

The immigrant nurses' approach of the patients was fundamental for them to feel accepted. The naturally adopt the "strategy" of seeking the patients' support as this represents an additional advantage in their adaptation process to an unknown culture.

\section{The cultural themes}

\section{In search of better horizons - the decision to immigrate to Chile}

The existence of many nurses, low remuneration, insufficient financial resources to purchase the goods needed to live and the lack of work for the great demand of nurses prepared in their countries of origin are the main reasons to look for a job in Chile. Professional development aspirations were also mentioned, in combination with better living conditions and quality of life as factors to consider in the decision to migrate. In addition, there are the scarce options and great difficulties to get access to specialization and professional development. These aspects act as catalysts in the decision to seek better professional development horizons.

Knowing the decision to emigrate and its reasons, concepts of country, origin, residence, affections and economic situation are related to Purnell's concepts in the domain Overview/heritage. In addition, the nurses' difficulties in the domain-Workforce issues were identified in terms of autonomy and gender role.

Uruguay gave me education, but not work (Lorena.uy); Colombia is saturated, you get money to survive (Berta.co); The quality of life was not good (Estela.co); [...] the remuneration is better here and a lot of doors are opened (Maria.co); [...] you get better opportunities [...] (Melissa.co).

In addition, their motivations to seek a new option in life and professional establishment with a view to gaining a better quality of life, which they did not have in their countries of origin, correspond to the search for social status in the nursing community. In that sense, 
Purnell's domain Gender roles and family organization is shown in their gender determination to emigrate and their project as members of a family in order to improve their lifestyle.

\section{Gaining trust and establishing a support network - employability and professional performance}

The nurses signaled many aspects that facilitate their employability and immediate start in their professional activities. The facilitators were the homologation of their degrees as a result of the bilateral recognition agreements between South American countries, the shortage of professionals in Chile and the familiarity with nurses from that country working at the hospitals. In addition, the nurses' change and establishment process was characterized by help from family members, friends, boyfriends or husbands.

These variables in the nurses' employability process, profession and affections fit into Purnell's domain-Overview/heritage.

Our documentation was facilitated through an agreement (María.co); [...] I arrived and started to work (Melissa.co); I live with friends, Uruguayans (Gladys.uy).

Upon arrival, the immigrant nurses immediately start to work because of the need for these professionals in Chile, which makes them feel very uncertain. The nursing team at the two hospitals includes auxiliary nurses, clinical nurses, head nurses and nurse supervisors. The work shifts vary from service to service. The foreign nurses are distributed across different shifts and hospital sectors and are involved in direct patient care.

In Chile, as from 1997, the nursing profession has been recognized by law, with three main functions: care management, execution of actions deriving from the diagnosis and medical treatment. Ministry of Health Decree 140, issued in 2004, establishes the Organic Regulation of Health Services in article 51, determining that "care management" comprises the actions aimed at the promotion, maintenance and restoration of health, the prevention of illnesses or injuries and the execution of activities deriving from the diagnosis and medical treatment and the duty to watch over the best management of patient care resources ${ }^{(12)}$.

In that sense, in their inclusion process, the immigrant nurses feel privileged for being valued as professionals, respected by their colleagues, patients and society as Health-care providers (domain), differently from their countries of origin, where demotivation was the dominant feeling.
The similarities in terms of professional education, particularly the technical aspects of care, facilitate the development of their professional activities. The educational level is also part of Purnell's domain Overview/heritage, which the immigrant nurses experience as positive.

[...] it's all very similar [...] (Andrea.br); the care is similar ... (María.co); [...] your experience is highly valued, you can advance and get further training (Estela.co); [...] the care is in accordance with your experiences and skills [...] (Karen.ec); your opinions are respected [...] (Nieves.uy); We are acknowledged by society $[. .$.$] (Berta.co).$

They suppose that your way of establishing personal contact, in a closer and more loving manner, contributes to the establishment of good relations. They feel that they are respected and well received by the patients. In the field notes, various occasions were registered when the nurses approached the patients gently and were corresponded with respect and gratitude in the nursing care process. The welcoming the patients demonstrate in response to the immigrant nurses' kindness helped to achieve a good professional performance. All aspects related to the principles of autonomy, acculturation, assimilation, gender roles and health-care practices are in accordance with Purnell's domain Workforce issues, and identified through their gentle approach of the patients.

The relation with the patients is good (Andrea.br); [...] we are loving and gentle to them [...] (Berta.co); [...] the patients are grateful for the attention [...] (Nieves.uy).

They naturally gain the patients' trust, establishing a support network in an unknown context.

\section{Seeking people's acceptance - professional adaptation in a new cultural scenario}

The immigrant nurses had to overcome some difficulties to get established in their new cultural and professional space. Their professional adaptation requires appropriate language in order to establish effective communication and be able to work. They look for the best way to do this with a view to getting accepted at work and avoiding misunderstandings.

They find it very important in this process to understand and be understood, with a view to an effective professional performance, achieved through appropriate and specific terms for the technical as well as the administrative aspects of care.

The semantic differences, expressions, slang, or changes in the meanings of the words and names of the materials the nurses use are indicated as obstacles 
when they start to work because they hamper the communication with their local colleagues, patients and other health team members.

Communication is a great problems for the professionals and, without face-to-face contact, they prepare as well as they can to gain their colleagues' respect. In that sense, it was observed and registered that the Brazilian nurse got "prepared", thought about how she should communicate before talking by phone with her Chilean colleagues from other hospital services.

The difficulties they presented to express their thoughts, ideas and feelings to local colleagues and other health professionals fit into Purnell's cultural domaincommunication, concerning contextual language use and its variations, such as non-verbal communication.

[...] they talk to you rapidly (Lucía.co); [...] I did not understand them at all [...] (Nieves.uy); [...] my words were disrespectful (Diana.uy); [...] the words and materials change [...] (Berta.co); [...] I am in doubt about the language to relate with the nurses (Andrea.br).

The immigrant nurses feel that the local nurses lack confidence in their professional education and they need to demonstrate their professional capacity in order to be accepted. The differences in some responsibilities, the distant and class-related relationship among health team members and the dependence on the physicians are frustrating experiences that demand additional efforts from the nurses with a view to their professional self-adaptation, making great effort to adapt in a new cultural context of work. This adaptation included overcoming the difficulties characteristic of professional practice and its cultural barriers ${ }^{(1)}$.

The diversification in the immigrant nurses' functions is opposed to the care that is relegated to mere practice, with the consequent loss of empowerment and professional profile, while feeling that these practices go against the expectations of the community receiving the care. Being a "clinical nurse" hampers their activities and makes them feel personally dissatisfied because of the loss of professional power they had in their country of origin. They think that the form of care management negatively influences the patients and their family and, consequently, the health services. These experiences exhaust their selfesteem and make their professional and family relations more difficult. They also mention different responsibilities in some care activities and the existence of a relation of dependence on the physicians or health-care practices that differ from their countries of origin.

The characteristics as Health-care providers (domain), their traditional practices, individual responsibility related to health, health practices and health and nursing care barriers are in accordance with the cultural beliefs in Purnell's domains.

Care goes beyond technical procedures. The understanding of how this process is experienced serves as the background to encourage reflection and autonomy in decision making ${ }^{(13)}$

They mistrust foreign nurses because of a lack of knowledge (Berta.co); they see you with constraints, question what you've learned [...] responsibilities are delegated, there's classism because of distancing in the team (María.co); [...] your hands are tied, I feel frustrated [...] (Lucía.co); It's complicated [...] (Lucía.co); [...] the adaptation is difficult [...] (Cristina.ec), [...] when you just deliver care, care management gets sloppy and you lose empowerment (Melissa.co).

The aspects that hamper the nurses' professional adaptation in Chile include experiences of rejection, professional relations that are questioned and unfair from colleagues, as well as vulnerability due to lack of support, feeling of helplessness and loneliness; overload and professional stress, discrimination and mistrust, all of which are frustrating experiences to adapt to the new job context. These experiences affect the relationship among people in the professional context and further to the family context.

Some nurses feel that the behaviors of rejection and direct or hidden discrimination in the professional context, such as the relationship between health team members in Chile and the immigrant nurses, can be related to the skin color or body height differences. The domain-Biocultural ecology includes the ethnic and racial variations that were perceived, such as skin color and body height differences.

[...] you feel racism, comments that make you quit your job, there's rejection (María.co); [...] it's another culture, you are exposed to suspicion and discrimination (Isabel.co); [...] they are reluctant to foreigners, I'm mulatto and look like a Peruvian [...] (Lucía.co).

Therefore, they resiliently remain silent so as not to get involved beyond professional issues and avoid going deeper into conflicts, in the attempt to feel accepted, which means gaining the natives' trust.

[...] you create defense, personality, live with it (Berta.co) [...] I make sure to do my job and not get involved (Karen.ec).

The nurses signaled that, to get established in the new cultural context, they had to overcome difficulties like Workforce issues (domain) in their process of autonomy, acculturation and assimilation, in the attempt to get accepted by all health team members, which means gaining their trust. 


\section{Discussion}

The nurses who immigrated to Chile manifest that, in their countries of origin, the job opportunities are scarce and badly paid with few possibilities for professional development.

The cultural competence in the processes identified in the decision to emigrate, in the employability and adaption of the nurses to the new culture is determined by the domains Overview/heritage, Communication, Workforce issues, Family roles and organization, Biocultural ecology and Health-care providers ${ }^{(9)}$. They manifest that their employability and professional performance are hampered by their need to adapt to the new culture and new professional context at the same time. The differences in the professional background, responsibilities and conceptions of the care management relationship lead to a loss of empowerment in nursing and make the immigrant nurses feel uncertain in the new cultural context.

Furthermore, we perceive that the main difficulty is related to the cultural barriers, to communication, marginalization, to the nurses' need to demonstrate their skills and to their relationship with colleagues ${ }^{(1-3)}$, besides the need to combine their different roles with feelings of rootlessness and the demands characteristic of a new lifestyle, which make them more vulnerable. Also, some nurses felt mistrust and discrimination from their colleagues, in accordance with research findings from Australia, USA and Canada(1-3). The adaptation includes overcoming the difficulties characteristic of the professional practice and its cultural barriers( ${ }^{(3,14)}$.

The immigrant nurses in Chile start to work at the hospitals in a phase unconsciously incompetent cultural awareness according to the Purnell Model to deliver care in the framework of the person, family, community and global society of the new country. Arriving in a new culture implies experiencing a constant tension due to the continuous effort to adapt, the burden of getting adjusted to the new society consciously and voluntarily. "People seeking acceptance" was the central cultural theme that emerged from the immigrant nursing who live and work in Chile. According to them, this represents a great challenge in their lives, which they cannot face alone, as they need to conciliate their objectives with the differences in the cultural environment of their personal and professional development in the new country.

Cultural competence is the development of a conscious and non-linear process, resulting from the adaptation to the care and culture. Cultural awareness departs from the unconsciously incompetent phase, without the awareness that one lacks knowledge about the new culture, until reaching the ideal phase of unconscious competence, when one automatically delivers care in accordance with the culture ${ }^{(9)}$.

At the international level, in response to the nurses' demands, intervention programs are proposed to improve the professionals' competence(2,14-15). In Ontario, there is a center to prepare and advise nurses educated abroad(16). In addition, the countries need to adapt their policies in order to improve the nurses job conditions, development bilateral programs to administer the migrations ${ }^{(17-18)}$.

Theoretical reflection is needed about nursing teaching, departing from the conceptualization of the globalized world and the repercussions of its paradigms on man and, consequently, on the nursing students' learning, validating the relevance of using a bio-psychosocial-economic model that values care for individuals in different contexts ${ }^{(19)}$, involving professionals from health institutions in this cultural change.

This preparation should include institutional analysis, the psychodynamics of work and the theory of communicative action. These three areas are distinct possibilities to consider both professional-user and professional-professional interactions ${ }^{(20)}$. Great effort is needed to identify and define the global health competences, as these are just beginning(21).

\section{Final considerations}

In general, the immigrant nurses in Chile are satisfied with their achievements, related to their professional life as well as their projects, expressing a level of conformity with their lifestyles in the achievement of their property targets.

The process of getting established as a nurse in the new country is characterized by facilities and difficulties. The main facilities involved the existence of job opportunities, some similarities in the professional education and support from patients. The difficulties were related to cultural aspects in changing the meaning of words and the use of slang that entail difficulties to understand and be understood, as well as the complex relationship with colleagues, lack of knowledge about health policies and new responsibilities in care management.

The professionals clearly need to get integrated in an unknown cultural environment, with different standards, beliefs and values in the social and care 
context, based on human conducts, communication and interpersonal relations.

The immigrant nurses in Chile start to work at the hospitals in a phase unconsciously incompetent cultural awareness according to the Purnell Model to deliver care in the framework of the person, family, community and global society of the new country. Arriving in a new culture implies experiencing a constant tension due to the continuous effort to adapt, the burden of getting adjusted to the new society consciously and voluntarily. "Seeking people's acceptance" was the central cultural theme that emerged from the immigrant nursing who live and work in Chile. According to them, this represents a great challenge in their lives, which they cannot face alone, as they need to conciliate their objectives with the differences in the cultural environment of their personal and professional development in the new country.

Further reflection is needed, focusing on the transition of immigrant nurses in Chile with a view to their professional integration. The health institutions need to make decisions that promote these educative aspects in all professionals, with a view to giving competent, fast and effective answers to their service needs.

This research validates the need to establish an adaptation period for the nurses who arrive in a new sociocultural and professional context. Its findings provide directions for organizational policy strategies for the sociocultural transition to the job world of nurses who arrive in Chile from South American countries. We believe that this study, based on the experiences of nurses, within a cross-cultural perspective, contributes to the knowledge about the post-modern paradigm and about the needs of our professionals in order to promote the quality of care at health services in the current context of globalization.

Great efforts have been made globally to define the cultural competences of nursing students that need to be incorporated into the curricula. In that sense, this study intends to contribute to the knowledge about the needs of health professionals, in this case nurses, in the context of inter-country mobility. Moreover, these research results provide evidence to international entities, academic researchers, health professionals and lecturers involved in continuing education at the institutions.

The professionals need to be offered support during the first year of their study, through educative programs and interventions aimed at achieving progress in their cultural awareness and at improving their level of competence.

\section{References}

1. Omeri A, Atkins K. Lived experiences of immigrant nurses in New South Wales, Australia: searching for meaning. Int J Nurs Studies. 2002;39:495-505.

2. Blythe J, Baumann $A$, Rhèaume $A$, McIntosh $K$. Nurse migration to Canada: pathways and pitfalls of the workforce. J Transcult Nurs. 2009;(20):202-10.

3. Hancock PK. Nurse migration: the impact on nursing education. Int Nurs Rev. 2008;55:258-64.

4. Malvárez SM, Muñoz González LA, Reyes Vidal A, Mandiola Muñoz E, Reyes Reyes C, Price Romero Y. Migración de Enfermeras de América Latina. Área de América de Sur. [Internet]. Washington (DC): Organización Panamericana de la Salud; 2011. (OPS. Serie Desarrollo de Recursos Humanos HSR, 60). [acesso 22 nov 2013]. Disponível em: www.paho.org/hq./index.php?...

5. Boelen C. Social accountability and excellence. Educ Méd. [Internet]. 2009 Dic [acesso 8 jul 2013]; 12(4):199-205. Disponível em: http://scielo.isciii.es/scielo.php?script=sci_ arttext\&pid=S1575-18132009000500001\&lng=es. http:// dx.doi.org/10.4321/S1575-18132009000500001

6. Rocha ESB, Nagliate $P$, Furlan CEB, Rocha $K$ Jr, Trevizan MA, Mendes IAC. Knowledge management in health: a systematic literature review. Rev. Latino-Am. Enfermagem. 2012;20:392-400.

7. Trevizan MA, Mendes IAC, Mazzo A, Ventura CAA. Investment in nursing human assets: education and minds of the future. Rev. Latino-Am. Enfermagem. 2010;18:467-71.

8. Leininger $M$. Culture care. A major contribution to advance transcultural nursing knowledge and practices. J Transcult Nurs. 2002;13:189-92.

9. Purnell LD. The Purnell's model for cultural competence. J Transc Nurs. 2002; 13:193-6.

10. Parfitt BA. Using Spradley: an ethnosemantic approach to research. J Adv Nurs. 1996;24:341-9.

11. Gaudlitz MH. Reflexiones sobre los principios éticos en investigación biomédica en seres humanos. Rev Chil Enf Respir. [Internet]. 2008 [acesso $14 \mathrm{fev}$ 2012]; 24(2):138-42. Disponivel em: http://www. scielo.cl/scielo.php?script $=$ sci_arttext\&pid $=$ S0717 73482008000200008\&lng=es. http://dx.doi.org/10.4067/ S0717-73482008000200008

12. Milos P, Borquez B, y Larrain AI. La "gestión del cuidado" en la legislación chilena: interpretación y alcance. Cienc Enferm. [Internet]. 2010 [acesso 18 fev 2013];16(1):17-29. Disponivel em: http://www.scielo.cl/scielo.php?script=sci_ arttext\&pid=S0717-95532010000100003\&lng=es . http://dx.doi.org/10.4067/S0717-95532010000100003 
13. Seima MD, Michel $T$, Méier $M J$, Wall $M L$, Lenardt $\mathrm{MH}$. Scientific nursing production and Madeleine Leininger's theory: integrated review 1985-2011. Esc Anna Nery. [Internet]. 2011 [acesso 3 ago 2012]; 15(4): 851-7. Disponível em: http://www. scielo.br/scielo.php?script $=$ sci_arttext\&pid=S141481452011000400027\&lng=en. http://dx

14. Konno R. Support for overseas qualified nurses in adjusting to Australian nursing practice: a systematic review. Int J Evid Based Healthc. 2006;(4):83-100.

15. McElmurry B, Solheim K, Kishi R, Coffia M, Woith W, Janepanish P. Ethics concerns. Prof Nurs. 22:226-35. 16. Pittman $P$, Aiken LH, Buchan J. International migration of nurses: introduction. Health Serv Res. 2007;42(3 Pt 2):1275-80.

17. Malvárez S, Castrillón MC. Panorama de la fuerza de trabajo en enfermería en América Latina. Segunda Parte. Rev Enferm IMSS. 2006;14:145-65.

18. Castrillón MC, Pensando en la formación de profesionales de enfermería en América Latina. Invest Educ Enferm. 2008;26(2 supl):114-21.

19. Scherer ZAP, Scherer EA. Reflections on nursing education in postmodernity and the metaphor of a theory-practice gap. Rev. Latino-Am. Enfermagem. 2007;15(3):498-501.

20. Carvalho BG, Peduzzi M, Mandú ENT, Ayres JRCM. Work and inter-subjectivity: a theoretical reflection on its dialectics in the field of health and nursing. Rev. Latino-Am. Enfermagem. 2012:20(1):19-26.

21. Wilson LL. Preparing nurses for global healthcare. [Editorial]. Rev. Latino-Am. Enfermagem. 2011; 19:1279-8. 